\title{
Commentary
}

\section{Global Rehabilitation - Addressing the Need for Early, Safe, Continuous and Widespread Rehabilitation in Low- and Middle-Income Countries}

\author{
Elisabeth Brogren ${ }^{1,}$, , Pernilla Vikstrom ${ }^{1}$, Stefan Johansson ${ }^{1}$, Nyaradzai Dangarembizi-Munambah ${ }^{2}$, \\ Theodora Chikwanha ${ }^{2}$, Faith Chengetayi Muchemwa ${ }^{2}$, Pat $\mathrm{McKee}^{3}$, Tingadini Nyoni ${ }^{4}$, \\ Midion Mapfumo Chidzonga ${ }^{2}$, Lars Bertil Dahlin ${ }^{1}$ \\ ${ }^{1}$ Department of Translational Medicine - Hand Surgery, Lund University, Skane University Hospital, Malmo, Sweden \\ ${ }^{2}$ College of Health Sciences, University of Zimbabwe, Harare, Zimbabwe \\ ${ }^{3}$ Department of Occupational Science and Occupational Therapy, University of Toronto, Toronto, Canada \\ ${ }^{4}$ Department of Plastic Surgery, Parirenyatwa Group of Hospital, Harare, Zimbabwe
}

\section{Email address:}

Elisabeth.Brogren@med.lu.se (E. Brogren),Pernilla.Vikstrom@med.lu.se (P. Vikstrom), Stefan.Johansson@skane.se (S. Johansson),

NyarieMnambah@live.com (N. Dangarembizi-Munambah), tchikwanha@medsch.uz.ac.zw (T. Chikwanha),

fcmuchemwa@yahoo.co.uk (F. C. Muchemwa),patmckee.ot@gmail.com (P. McKee), tinganyoni@gmail.com (T. Nyoni),

mtmchidzonga@yahoo.com (M. M. Chidzonga), Lars.Dahlin@med.lu.se (L. B. Dahlin)

${ }^{*}$ Corresponding author

\section{To cite this article:}

Elisabeth Brogren, Pernilla Vikstrom, Stefan Johansson, Nyaradzai Dangarembizi-Munambah, Theodora Chikwanha, Faith Chengetayi Muchemwa, Pat McKee, Tingadini Nyoni, Midion Mapfumo Chidzonga, Lars Bertil Dahlin. Global Rehabilitation - Addressing the Need for Early, Safe, Continuous and Widespread Rehabilitation in Low- and Middle-Income Countries. Clinical Medicine Research. Vol. 10, No. 2, 2021, pp. 35-39. doi: 10.11648/j.cmr.20211002.11

Received: August 31, 2020; Accepted: March 8, 2021; Published: March 30, 2021

\begin{abstract}
Background: Scaling-up surgical care is one of the most important goals in improving global health and long-term development, where specific attention is directed towards diagnosis and treatment of traumatic injuries, as well as to certain conditions, with varying frequencies between continents and countries. Successful outcome after surgery depends also on safe, efficient and widespread rehabilitation, including both short- and long-term engagement of physiotherapists and occupational therapists. However, relatively little attention has been paid to rehabilitation after trauma and surgery for injuries and various conditions in a global perspective. In fact, the access to rehabilitation in low- and middle-income countries (LMIC) is believed to be enormous. Objective: Through a shared project between two University Hospitals in Zimbabwe and Sweden, our objective was to create an academic partnership with the goal of improving rehabilitation after hand injuries in Zimbabwe. Results: Except geographical, political and patient-related factors, we found that prolonged or inadequate immobilisation after hand injuries and poor teamwork between surgeons and therapists were important factors that complicated the patient care. We give examples on how educational programs in rehabilitation could be organized with focus on creating a close alliance between surgeons and therapists. Conclusion: Creating academic partnerships between universities and hospitals can be of mutual benefit and may be a model for spreading knowledge and strengthen health care systems. Collaboration between therapists and surgeons can be strengthened through integrated courses adapted to existing local circumstances, exchange programs and on-line education, which can be organized between specific departments in different countries. We launch the concept of Global Rehabilitation and give examples of how teaching posttraumatic and postoperative management of hand surgical injuries and common conditions could be structured.
\end{abstract}

Keywords: Global Rehabilitation, Low and Middle Income Countries, Physiotherapy, Occupational Therapy, Surgery, Hand Surgery 


\section{Introduction}

Despite tremendous improvements in surgery, advancements have not been uniform across the world. The majority of the population in the world do not have access to safe and affordable surgical and anaesthesia care [1]. To improve global surgical treatment, the Lancet commission highlighted the need for safe and affordable surgical and anaesthesia care to reduce death and disability and increase welfare and economic growth in low- and middle-income countries (LMIC) [1]. Despite a growing need for surgical and anaesthesia care in LMICs, development has stagnated or regressed and the greatest unmet needs for surgery are found in Africa [1]. Over the last two decades, the global disease burden has shifted from communicable, maternal, neonatal and nutritional disorders to a rising burden from mental and behavioural disorders, musculoskeletal disorders and diabetes [2]. Trauma and musculoskeletal impairment are in fact the main causes of functional disability and severe pain worldwide, where appropriate and prompt diagnosis and treatment is particularly essential [2]. In sub-Saharan Africa, there is an urgent need for improved access to emergency services, rehabilitation facilities, surgical equipment and highly trained surgical and allied health personnel to perform critical orthopaedic procedures [3]. Also, the global hand surgery landscape has been emphasized in this context, although high-quality data on the epidemiology, management and consequences of hand injuries in LMICs is lacking [4-6]. The International Federation of Societies for Surgery of the Hand (IFSSH) has recently raised the issue of inadequate access to safe surgical and postoperative management of hand injuries and urges high income countries (HICs) to help LMICs in building local capacity through education [7].

A substantial risk for patients in LMICs is a delay in receiving care, causing high case-fatality rates for common and sometimes easily treated conditions. Counteracting delayed treatment, together with prevention strategies, is crucial to improve outcome in diagnoses related to the increased incidence of cancer, traffic accidents and cardiovascular and metabolic diseases in LMICs [1].

The Lancet commission on Global Surgery have embedded surgical and anaesthesia care in LMICs within the agenda, advocating an outreach to the community and with an integral component of existing health networks for care provision [1]. Recommendations for work force, training, education and research activities were also made, which emphasized economics and investment scale-up [1].

\subsection{Hand Surgery in a Global Perspective}

Hand surgical injuries faces its own challenges in the global perspective, often over-looked as less important compared to life-threatening conditions. However, hand and upper extremity function is closely linked to productivity and economic growth [8]. In fact, hand and wrist injuries results in higher costs compared to both lower limb and brain injuries when taking productivity loss into account [9]. Many hand-injured patients are young and otherwise healthy, and may be deprived of their independence, self-sufficiency and working ability for the rest of their lives with severe consequences for any related family. Although the extent of persistent disability after severe hand injuries in LMIC is not well studied, it is reasonable to assume that upper extremity trauma accounts for considerable financial loss for individuals and community in these countries [4]. With increased economic development and rapid industrialization in LMICs, the incidence of hand injuries is even forecasted to rise [4]. Thus, hand surgical expertise can make a significant difference in a global perspective [5, 10]. The need for education and development of the hand surgical discipline in LMICs has been recognized, although the availability of such education is still lagging behind [6]. There is also an urgent need for proper outcome measurements, such as patient-reported outcome measurements (PROMs), that could easily be implemented in LMICs, but such evaluation instruments have to be reliable and validated for the specific country or continent [11].

The field of Hand Surgery deals with surgical and non-surgical treatments of conditions and injuries of the hand and upper extremity, where all types of affected tissues should be considered. Frequently, several tissue components are involved in the hand and upper extremity after trauma, which is a challenge both in perspective of the surgeon and the therapists. The hand surgeon needs to master a broad range of surgical skills, including microsurgery and orthopaedic and plastic surgery techniques, which should be based on knowledge about involved basic and relevant biological healing processes. To improve health and functional outcomes, early mobilisation and the concept of teamwork permeates through all treatment strategies, making the hand therapist one of hand surgeons closest allies.

In Ethiopia, the vast majority of hand injuries occur at work, most commonly involving wood working machines. Most of these injuries are treated nonoperatively because of lack of operative facility. Only $17 \%$ of the patients have access to physiotherapy. Inadequate immobilisation is common; $36 \%$ were immobilised in a non-functional position, involving unnecessary joints (33\%) and for prolonged time (40\%), resulting in overall poor patient-reported satisfaction ratings [12]. Similar reports from Nigeria, Kenya and Uganda have shown that work-related injuries and traffic injuries are common and most often affect the upper extremity [13-15]. Poorly equipped facilities for acute treatment of burn injuries and residual problems and disability after non-treated burns are specific problems in LMICs, with a risk for specifically affecting children, where the number of cases may be related to an increased use of open fire in food cooking as well as inappropriately protected electrical equipment and cables [16, 17].

\subsection{Global Rehabilitation}

Adequate and early rehabilitation after injuries and surgery is crucial to improve outcome and shorten time off from work 
$[3,9]$. Rehabilitation should be recognized as an essential adjunct to surgical treatment [10]. There are limited data on the access to rehabilitation services in developing countries, although the unmet needs are thought to be tremendous [18]. According to estimates by the World Health Organization, there are fewer than 10 skilled rehabilitation practitioners per million population in LMICs [19]. In conformity with the purpose of Global Surgery, we emphasize the need for Global Rehabilitation, in which there is a mutual interest in education and learning from each other in a global perspective.

\subsection{Hand Surgery and Rehabilitation in Sweden and Zimbabwe}

In Sweden, a country with a population of 10.2 million inhabitants, Hand Surgery is recognized as a speciality of its own since 1969 [20]. A multidisciplinary approach, with close collaboration between hand surgeons and rehabilitation personnel, is fundamental. In 2018, there were 13 hand surgeons per million population in Sweden [21]. However, basic hand surgery is also performed by orthopaedic surgeons (147 per million population the same year) [21]. In 2020, there were 44 occupational therapists and 29 physiotherapists employed at any of the hand surgery departments, thus with a high level of expertise. During the same year, the Swedish Society for Hand Rehabilitation had 200 members, also including therapists with special interest in hand rehabilitation, but based in primary care or at orthopaedic departments. Over the past several decades, the spectrum of hand injuries has changed in Sweden, with a decreased number of work-related, severe hand injuries and an increase of leisure-related injuries [22]. Thus, there are potential limitations concerning the breadth of experience in specific and severe hand injury cases among younger hand surgeons and hand therapists in Sweden.

Zimbabwe has a population of 14.8 million inhabitants. There are no trained hand surgeons in the country, although some hand surgical procedures are performed by the four practicing plastic surgeons ( 0.03 per million population) and 38 orthopedic surgeons ( 0.26 per million population).

There were only 432 physiotherapists (29 per million population) practising in the country in 2018 as compared to 1680 per million population in Sweden the same year [19, 21]. Data on occupational therapists, or whether there are any rehabilitation personnel with specific hand training, is not available. According to the current National Health Strategy for Zimbabwe (2016-2020), the effective coverage for rehabilitation is low at $30 \%$ owing to the low rehabilitation practitioner to patient ratio [23]. This has been worsened by the exodus of rehabilitation professionals for better opportunities and career advancements outside the country. The goal to retain and attract back rehabilitation practitioners remains a huge challenge [23]. Whilst other countries have developed specialty areas, including hand rehabilitation as one of these areas, Zimbabwe has lagged behind on this aspect. Therefore, there is an urge for improving the availability of rehabilitation in terms of trained personnel, equipment and supplies in order to strengthen clinical skills for early detection and management of injuries and disabilities [6, 10, 23]. There is need to set up specialized hand surgery and rehabilitation units, with a multi-disciplinary approach in Zimbabwe and other LMICs, which also should include the value of research $[5,10,24]$. The purpose of our shared project was to create an academic partnership with the long-term goal of improving the posttraumatic and postoperative management of hand surgical injuries in Zimbabwe.

\section{Forming Partnerships}

UNESCO has adopted a global, sustainable development agenda, with one goal to improve education by 2030 . Education at all levels can reduce inequality and break the cycle of poverty [25]. Beside governmental and nongovernmental organizations, we believe that universities, in collaboration with the health care system in HICs, have a responsibility and an important role in assisting LMICs with higher education $[5,26]$.

We initiated a collaboration between Lund University in Sweden and Harare University Hospital in Zimbabwe with the goal of improving principles for treatment and rehabilitation after hand injuries. It is our belief that high-quality care is possible in resource-limited facilities, assuming that the personnel have adequate training and knowledge. Short-term hand surgical mission trips have shown to be cost-effective, especially for simple conditions and when no other options are available [27, 28]. However, it is through training and education, often repeated, of local health-care providers that a sustainable system can be established [7, 28, 29]. It has been emphasized that this type of training should be performed by experienced teachers, adapted to existing circumstances of the host country and with sustainable education programs [6, 24].

In Zimbabwe, as in many LMICs, shifting of tasks to less-specialized health workers, brain-drain and limited resources challenge the health-care system [3, 26, 30]. From our collaboration, we identified specific hand injury-related problems in Zimbabwe in terms of a) excessively long time between injury and surgical care, b) prolonged and sometimes inadequate immobilization after hand injuries, c) low patient adherence to treatment recommendations, d) inability to reach hospitals and rehabilitation facilities due to inadequate transportation and e) lack of teamwork between surgeons and rehabilitation personnel. The educational program was designed to emphasise the team concept between surgeons and therapists. A crucial point is the timing and initiation of the rehabilitation, since biological tissue reactions after injury and surgical procedures increase the risk of developing fibrosis, particularly in complex injuries affecting several tissue components. Early and adequate rehabilitation after hand injuries should be considered as important as the surgical procedure itself, to ensure the best possible outcome.

\subsection{Course in Hand Rehabilitation}

Our collaboration includes a course in hand rehabilitation after acute hand trauma, supported by Anatomy Softwear International Inc. (Figure 1). The course takes place in Harare 
and includes lectures, anatomical principles illustrated by the Anatomy glove, clinical case discussions, hands-on examination of the upper extremity and workshops, where the participants learn how to produce simple, but safe, orthoses in cast. Two hand surgeons, one occupational therapist and one physiotherapist from Sweden participates as instructors and the course is open for practising therapists, students in occupational- or physiotherapy and orthopaedic or plastic surgeons based in Zimbabwe. Generally, the course evaluation has shown a median score of $>4 / 5$ for the provided lectures and case discussions with $>98 \%$ of the participants considering that the course met their expectations. More than $95 \%$ of the participants also considered the course being useful in their profession to a high or very high degree.

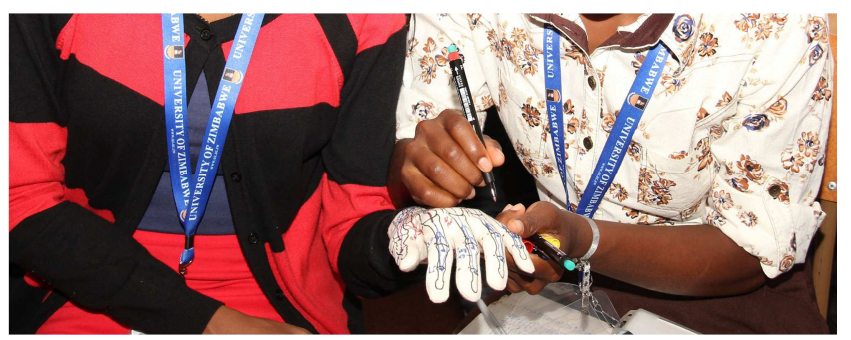

Figure 1. Practical exercise in hand anatomy during a course in rehabilitation after hand injuries using the Anatomy Glove in Harare, Zimbabwe.

\subsection{Fellowship for Hand Therapists}

A short fellowship program for students in occupational therapy and physiotherapy has started, where students from the University in Harare visits the department of hand surgery in Malmö, Sweden. For two months, the students are trained in different rehabilitation skills by occupational therapists and physiotherapist with long experience of hand injuries.

\subsection{Online Self-learning Course for Surgeons}

We have also introduced an online self-learning course for residents in plastic and orthopaedic surgery, using a comprehensive textbook in hand surgery [31]. Weekly reading assignments of 7-9 pages are sent to the participants on e-mail, together with four multiple choice questions. The correct answers are returned along with a corrective form were the participants themselves could see how they responded.

\section{Conclusions}

In conclusion, we recommend strengthening the collaboration between therapists and surgeons should be done through integrated courses and fellowships adapted to existing local circumstances from a global perspective with an exchange program between university or hospital departments in countries across the continents. A close alliance between therapists and surgeons during care of the patient is crucial for successful outcome. Thus, in accordance with a global surgical perspective to manage patients, we launch the concept of Global Rehabilitation.

\section{Funding}

Zimbabwe - global health project (no specific project no.) The Anatomy Gloves and instructional videos were provided by Anatomy Softwear International Inc.

\section{Competing Interests}

The authors declare that they have no competing interests.

\section{Ethics Approval and Consent to Participate}

Not applicable.

\section{Acknowledgements}

We thank Karin Frydenlund and Tina Folker for support.

\section{References}

[1] Meara JG, Leather AJ, Hagander L, Alkire BC, Alonso N, Ameh EA, et al. Global Surgery 2030: evidence and solutions for achieving health, welfare, and economic development. Lancet. 2015 Aug 8; 386 (9993): 569-624.

[2] Murray CJ, Vos T, Lozano R, Naghavi M, Flaxman AD, Michaud C, et al. Disability-adjusted life years (DALYs) for 291 diseases and injuries in 21 regions, 1990-2010: a systematic analysis for the Global Burden of Disease Study 2010. Lancet. 2012 Dec 15; 380 (9859): 2197-223.

[3] Chokotho L, Jacobsen KH, Burgess D, Labib M, Le G, Peter N, et al. A review of existing trauma and musculoskeletal impairment (TMSI) care capacity in East, Central, and Southern Africa. Injury. 2016 Sep; 47 (9): 1990-5. Epub 2016/05/15

[4] Siotos C, Ibrahim Z, Bai J, Payne RM, Seal SM, Lifchez SD, et al. Hand injuries in low- and middle-income countries: systematic review of existing literature and call for greater attention. Public Health. 2018 Sep; 162: 135-46. Epub 2018/07/30.

[5] Chung KY. The Role for International Outreach in Hand Surgery. J Hand Surg Am. 2017 Aug; 42 (8): 652-5.

[6] Lam W, Jones J, Hodgson S, Jemec B. Hand surgery status in the African continent and efforts of hand surgeons from the United Kingdom. J Hand Surg Eur Vol. 2020 Jun; 45 (5): 536-40. Epub 2020/02/13.

[7] Agarwal-Harding KJ, Amlani LM, Dyer GSM, Mudgal CS. Addressing the global need for hand surgery. IFSSH: Hand Surgery Worldwide: Global Perspective. 2021 February 2021; 11 (1).

[8] Giladi AM, Ranganathan K, Chung KC. Measuring Functional and Patient-Reported Outcomes After Treatment of Mutilating Hand Injuries: A Global Health Approach. Hand Clin. 2016 Nov; 32 (4): 465-75. Epub 2016/10/08.

[9] de Putter CE, Selles RW, Polinder S, Panneman MJ, Hovius SE, van Beeck EF. Economic impact of hand and wrist injuries: 
health-care costs and productivity costs in a population-based study. J Bone Joint Surg Am. 2012 May 2; 94 (9): e56. Epub 2012/05/04.

[10] Riggs J, Chung KC. Postoperative Management of Hand Surgery in the Low- and Middle-Income Countries. Hand Clin. 2019 Nov; 35 (4): 403-10. Epub 2019/10/06.

[11] Bernstein DN, Agarwal-Harding KJ, Dyer GSM, Rozental TD. Outcomes Measurement in Global Hand Surgery. J Hand Surg Am. 2020 Sep; 45 (9): 865-8. Epub 2020/07/12.

[12] Ahmed E. The Management Outcome of Acute Hand Injury in Tikur Anbessa University Hospital, Addis Ababa, Ethiopia. East and Central African Journal of Surgery. 2010 March/April 2010; 15 (1): 48-56.

[13] Ihekire O, Salawu SA, Opadele T. International surgery: causes of hand injuries in a developing country. Can J Surg. 2010 Jun; 53 (3): 161-6. Epub 2010/05/29.

[14] Kaisha WO, Khainga S. Causes and pattern of unilateral hand injuries. East Afr Med J. 2008 Mar; 85 (3): 123-8. Epub 2008/07/31.

[15] Balikuddembe JK, Ardalan A, Stephen KM, Raza O, Khorasani-Zavareh D. Risk factors associated with road traffic injuries at the prone-areas in Kampala city: a retrospective cross-sectional study. J Inj Violence Res. 2020 Sep 29; 13 (1). Epub 2020/10/04.

[16] Sasor SE, Chung KC. Upper Extremity Burns in the Developing World: A Neglected Epidemic. Hand Clin. 2019 Nov; 35 (4): 457-66. Epub 2019/10/06.

[17] Chung KY, Hanemaayer A, Poenaru D. Pediatric Hand Surgery in Global Health: The Role for International Outreach. Ann Plast Surg. 2017 Feb; 78 (2): 162-70. Epub 2017/01/13.

[18] Bright T, Wallace S, Kuper H. A Systematic Review of Access to Rehabilitation for People with Disabilities in Low- and Middle-Income Countries. Int J Environ Res Public Health. 2018 Oct 2; 15 (10). Epub 2018/10/04.

[19] World Health Organization. Rehabilitation 2030: a call for action. 2018 [April 24, 2018]; Available from: http://who.int/disabilities/care/rehab-2030/en/.

[20] Hagert CG. The history of hand surgery in Sweden. J Hand Surg Br. 2001 Feb; 26 (1): 78-83. Epub 2001/02/13.

[21] Statistical database for surgical interventions [database on the
Internet]. 2008. Available from: https://sdb.socialstyrelsen.se/if_per/val.aspx.

[22] Rosberg HE, Dahlin LB. Epidemiology of hand injuries in a middle-sized city in southern Sweden: a retrospective comparison of 1989 and 1997. Scand J Plast Reconstr Surg Hand Surg. 2004; 38 (6): 347-55.

[23] Ministry of Health and Child Care. The National Health Strategy for Zimbabwe 2016-2020. 2016.

[24] Deptula P, Chang K, Chang J. Teaching Hand Surgery in the Developing World: Utilizing Educational Resources in Global Health. Hand Clin. 2019 Nov; 35 (4): 411-9. Epub 2019/10/06.

[25] UNESCO. UNESCO moving forward the 2030 Agenda for Sustainable Development. 2017.

[26] Brouillette MA, Kaiser SP, Konadu P, Kumah-Ametepey RA, Aidoo AJ, Coughlin RC. Orthopedic surgery in the developing world: workforce and operative volumes in Ghana compared to those in the United States. World J Surg. 2014 Apr; 38 (4): 849-57. Epub 2013/11/13.

[27] Tadisina KK, Chopra K, Tangredi J, Thomson JG, Singh DP. Helping hands: a cost-effectiveness study of a humanitarian hand surgery mission. Plast Surg Int. 2014; 2014: 921625. Epub 2014/09/17.

[28] Shrime MG, Sleemi A, Ravilla TD. Charitable platforms in global surgery: a systematic review of their effectiveness, cost-effectiveness, sustainability, and role training. World J Surg. 2015 Jan; 39 (1): 10-20. Epub 2014/04/01.

[29] Toobaie A, Emil S, Ozgediz D, Krishnaswami S, Poenaru D. Pediatric surgical capacity in Africa: Current status and future needs. J Pediatr Surg. 2017 May; 52 (5): 843-8. Epub 2017/02/09.

[30] Omoke NI, Chukwu CO, Madubueze CC, Egwu AN. Traumatic extremity amputation in a Nigerian setting: patterns and challenges of care. Int Orthop. 2012 Mar; 36 (3): 613-8. Epub 2011/07/23.

[31] Ozer K, Wolf JM, Watkins B, Hak DJ. Comparison of 4 fluoroscopic views for dorsal cortex screw penetration after volar plating of the distal radius. J Hand Surg Am. 2012 May; 37 (5): 963-7. Epub 2012/04/07. 